OPEN ACCESS

Edited by:

Yuji Morita,

Aichi Gakuin University, Japan

Reviewed by: Mattias Collin

Lund University, Sweden

Hyunwoo Lee,

University of Illinois at Chicago, USA

${ }^{*}$ Correspondence:

Molly A. Hughes

mah3x@virginia.edu

Specialty section:

This article was submitted to

Infectious Diseases,

a section of the journal

Frontiers in Microbiology

Received: 19 January 2017

Accepted: 10 April 2017

Published: 27 April 2017

Citation:

Margulieux KR, Liebov BK

Tirumala VSKKS, Singh A,

Bushweller JH, Nakamoto RK and

Hughes MA (2017) Bacillus anthracis

Peptidoglycan Integrity is Disrupted by the Chemokine CXCL10 through

the FtsE/X Complex.

Front. Microbiol. 8:740.

doi: 10.3389/fmicb.2017.00740

\section{Bacillus anthracis Peptidoglycan Integrity Is Disrupted by the Chemokine CXCL10 through the FtsE/X Complex}

\author{
Katie R. Margulieux ${ }^{1}$, Benjamin K. Liebov' ${ }^{2}$, Venkata S. K. K. S. Tirumala ${ }^{3}$, Arpita Singh ${ }^{1}$, \\ John H. Bushweller ${ }^{3}$, Robert K. Nakamoto ${ }^{3}$ and Molly A. Hughes ${ }^{1 *}$
}

${ }^{1}$ Division of Infectious Diseases and International Health, Department of Medicine, School of Medicine, University of Virginia, Charlottesville, VA, USA, ${ }^{2}$ Department of Chemistry, University of Virginia, Charlottesville, VA, USA, ${ }^{3}$ Department of

Molecular Physiology and Biological Physics, University of Virginia, Charlottesville, VA, USA

The antimicrobial activity of the chemokine CXCL10 against vegetative cells of Bacillus anthracis occurs via both bacterial FtsE/X-dependent and-independent pathways. Previous studies established that the FtsE/X-dependent pathway was mediated through interaction of the $\mathrm{N}$-terminal region(s) of CXCL10 with a functional FtsE/X complex, while the FtsE/X-independent pathway was mediated through the C-terminal $\alpha$-helix of CXCL10. Both pathways result in cell lysis and death of $B$. anthracis. In other bacterial species, it has been shown that FtsE/X is involved in cellular elongation though activation of complex-associated peptidoglycan hydrolases. Thus, we hypothesized that the CXCL10-mediated killing of vegetative cells of $B$. anthracis through the FtsE/X-dependent pathway resulted from the disruption of peptidoglycan processing. Immunofluorescence microscopy studies using fluorescent peptidoglycan probes revealed that incubation of $B$. anthracis Sterne (parent) strain with CXCL10 or a C-terminal truncated CXCL10 (CTTC) affected peptidoglycan processing and/or incorporation of precursors into the cell wall. B. anthracis $\Delta$ ftsX or ftsE(K123AVD481N) mutant strains, which lacked a functional FtsE/X complex, exhibited little to no evidence of disruption in peptidoglycan processing by either CXCL10 or CTTC. Additional studies demonstrated that the $B$. anthracis parent strain exhibited a statistically significant increase in peptidoglycan release in the presence of either CXCL10 or CTTC. While $B$. anthracis $\Delta f t s X$ strain showed increased peptidoglycan release in the presence of CXCL10, no increase was observed with CTTC, suggesting that the FtsE/X-independent pathway was responsible for the activity observed with CXCL10. These results indicate that FtsE/X-dependent killing of vegetative cells of $B$. anthracis results from a loss of cell wall integrity due to disruption of peptidoglycan processing and suggest that FtsE/X may be an important antimicrobial target to study in the search for alternative microbial therapeutics.

Keywords: Bacillus anthracis, chemokine, CXCL10, antimicrobial, FtsE/X, peptidoglycan 


\section{INTRODUCTION}

Chemokines are a large family of proteins that mediate the recruitment of leukocytes during the innate and adaptive immune response (Rossi and Zlotnik, 2000; Zlotnik and Yoshie, 2000, 2012). Interestingly, a number of chemokines have also been shown to have a direct antimicrobial effect against a wide variety of pathogens (Cole et al., 2001; Durr and Peschel, 2002; Yang et al., 2003; Crawford et al., 2009; Nguyen and Vogel, 2012; Yung and Murphy, 2012; Schutte et al., 2016). Among these chemokines, the human interferon$\gamma$-inducible, Glu-Leu-Arg negative [ELR(-)] CXC chemokines, CXCL9, CXCL10, and CXCL11 have direct antimicrobial activity against vegetative cells of Bacillus anthracis (Crawford et al., 2009, 2010, 2011; Margulieux et al., 2016). B. anthracis is a Gram-positive, spore-forming bacterium that causes the disease anthrax (Mock and Fouet, 2001). Because recombinant human CXCL10 was the most potent against vegetative cells of B. anthracis (Crawford et al., 2009), we focused our attention on the antimicrobial effects of this chemokine. A screen of a transposon mutant library of $B$. anthracis Sterne strain for resistance to CXCL10 led to the identification of the bacterial protein FtsX as being important in mediating the bactericidal effect of CXCL10, a finding that was verified in a fts $X$ deletion mutant, B. anthracis $\Delta f t s X$ (Crawford et al., 2011). FtsX is the membrane component of FtsE/X, a complex that has been shown in a variety of Gram-positive, Gram-negative, and acid-fast bacterial species to be involved in activating cell wall hydrolases that impact peptidoglycan remodeling during cellular elongation (Gram-positive) or division (Gram-negative) (de Leeuw et al., 1999; Bernatchez et al., 2000; Schmidt et al., 2004; Mir et al., 2006, 2015; Reddy, 2007; Garti-Levi et al., 2008; Domínguez-Cuevas et al., 2013; Meisner et al., 2013; Bartual et al., 2014; Mavrici et al., 2014). Peptidoglycan remodeling is a tightly regulated process such that a sudden disruption in the process may result in loss of cell wall integrity and bacterial cell death. A similar phenomenon has been observed with penicillin and other beta-lactam antibiotics (Kohanski et al., 2010). Thus, FtsE/X may be an important bacterial target for development of new antimicrobial strategies (Bugg et al., 2011; Typas et al., 2011).

CXCL10 is a small $10-\mathrm{kD}$ protein that has anstructured $\mathrm{N}$-terminal region, three anti-parallel $\beta$-strands, and an amphipathic C-terminal $\alpha$-helix (Cole et al., 2001; Frederick and Clayman, 2001; Booth et al., 2002; Swaminathan et al., 2003). Notably, the positively charged, amphipathic $\alpha$-helix has been generally thought to be responsible for the observed antimicrobial activity of the molecule because of the overall charge and structural similarity to defensins or cationic antimicrobial peptides (Brogden, 2005; Yeaman and Yount, 2007; Holdren et al., 2014). Recently, we observed that a C-terminal truncated CXCL10 (designated CTTC) retained antimicrobial activity (albeit, with somewhat less potency) against $B$. anthracis Sterne strain (hereby designated parent strain), but not against $B$. anthracis $\Delta f t s X$ (Margulieux et al., 2016). A second $B$. anthracis mutant strain was generated to test if a functional FtsE/X complex was required for CXCL10-mediated killing of $B$. anthracis vegetative cells. FtsE is an ATP-binding protein with conserved Walker $\mathrm{A}$ and $\mathrm{B}$ sites that are required for the hydrolysis of ATP to ADP and, in the presence of FtsX, co-localizes to the cell membrane (Arends et al., 2009; Domínguez-Cuevas et al., 2013; Sham et al., 2013; Mir et al., 2015). A mutant strain [B. anthracis ftsE(K123A/D481N)] was constructed with point mutations within the Walker A and B sites to eliminate its ability to hydrolyze ATP (Schmidt et al., 2004; Domínguez-Cuevas et al., 2013; Meisner et al., 2013; Mir et al., 2015; Margulieux et al., 2016). B. anthracis ftsE(K123A/D481N) showed intermediate resistance to CXCL10 and full resistance to CTTC, similar to results with the $\Delta f t s X$ strain, suggesting that the FtsE/X-dependent pathway of CXCL10-mediated killing requires an active FtsE/X complex and that FtsX alone is not sufficient (Margulieux et al., 2016). Results of membrane depolarization studies showed that CXCL10 caused membrane disruption of the $B$. anthracis parent and $\Delta f t s X$ strains; in contrast, CTTC caused membrane depolarization only in the parent strain and had no effect on the $\Delta f t s X$ strain (Margulieux et al., 2016). Thus, CXCL10 acts as a bifunctional antimicrobial molecule against vegetative cells of $B$. anthracis through FtsE/X-dependent and -independent mechanisms (Margulieux et al., 2016). The FtsE/X-dependent mechanism requires the $\mathrm{N}$-terminal region of CXCL10; whereas, the FtsE/X-independent pathway is mediated through the C-terminal $\alpha$-helix and/or other structural regions of CXCL10.

While FtsE/X has been identified as being important for the CXCL10 killing of $B$. anthracis, the mechanism of FtsE/X-dependent killing remains unknown. Peptidoglycan processing is an essential function for bacterial growth and cell division, and a disruption in peptidoglycan processing has a detrimental effect on the cell wall, leading to cell death (Vollmer and Seligman, 2010; Bugg et al., 2011; Reith and Mayer, 2011; Typas et al., 2011; Lovering et al., 2012; Vollmer, 2012; Sobhanifar et al., 2013). FtsE/X has been shown to be involved in peptidoglycan remodeling (Garti-Levi et al., 2008; Domínguez-Cuevas et al., 2013; Meisner et al., 2013). Thus, an inhibition or disruption of the complex by CXCL10 may interfere with peptidoglycan processing, resulting in a loss of cell integrity and cell death. Recent advances in peptidoglycan imaging technology allows for a more detailed study into how peptidoglycan remodeling is affected in the presence of antimicrobial molecules (Kuru et al., 2012, 2015; Liechti et al., 2014; Boersma et al., 2015). This new technology was used to study the antimicrobial effect of CXCL10 on peptidoglycan processing in $B$. anthracis vegetative cells. To assess peptidoglycan incorporation or release, we used two separate, yet complementary methods. One method utilized fluorescence confocal microscopy to visualize the uptake and incorporation of fluorescent-labeled amino acids into the peptidoglycan. The second method utilized a mammalian NF- $\kappa \beta$-based reporter cell line that overexpressed NOD2 to measure the release of peptidoglycan subunits. Our findings indicate that the interaction of CXCL10 with FtsX resulted in an increase in peptidoglycan release mediated via the FtsE/X-dependent pathway, which contributes to cell lysis through the loss of structural integrity. 


\section{MATERIALS AND METHODS}

\section{Bacterial Strains and Culture Conditions}

Bacillus anthracis Sterne strain $7702\left(\mathrm{pXO}^{+}, \mathrm{pXO}^{-}\right.$, American Type Culture Collection, Manassas, VA, USA) was used in these experiments and designated as parent strain. B. anthracis $\Delta f t s X$ and $B$. anthracis $f t s E(K 123 A / D 481 N)$ were derived from the Sterne strain as previously described (Crawford et al., 2011; Margulieux et al., 2016). Vegetative cells were prepared by inoculating B. anthracis parent strain spore stocks or B. anthracis mutant strain vegetative cell frozen stocks into $10 \mathrm{ml}$ of brain heart infusion (BHI) broth (Difco, Franklin Lakes, NJ, USA) and incubating overnight at $37^{\circ} \mathrm{C}$ with shaking (250 rpm). Mid-log phase cultures were prepared the following day by diluting the overnight culture 1:20 in fresh BHI broth followed by incubation at $37^{\circ} \mathrm{C}$ with shaking for $\sim 2 \mathrm{~h}$ until the culture reached an optical density at $600 \mathrm{~nm}\left(\mathrm{OD}_{600}\right)$ between 0.6 and 0.65 , at which time the cells were used for experiments. All laboratory work involving $B$. anthracis Sterne or Sterne-derived strains was approved through the University of Virginia Institutional Biosafety Committee. Biosafety level 2 practices were used for all work involving B. anthracis Sterne or Sterne-derived strains.

\section{Single Labeling of Peptidoglycan with EDA}

Recent advances in the field of peptidoglycan labeling have resulted in the development of a variety of fluorescent probes for amino acids that are incorporated into the peptide side chain of peptidoglycan during cell growth and division (Kuru et al., 2012, 2015; Popham, 2013; Liechti et al., 2014, 2016; Boersma et al., 2015). Ethynyl-D-alanine (EDA) is a D-alanine molecule with an additional alkyne group that can be "clicked" together, using the principles of "click" chemistry, with fluorophores containing a reactive azide group, through a copper-mediated reaction, resulting in a stable, coupled conjugate (Kolb et al., 2001).

EDA [(S)-2-Amino-4-pentynoic acid] (Boaopharma, Inc., Natick, MA, USA) was dissolved in $\mathrm{H}_{2} \mathrm{O}$ and used at a concentration of $1 \mathrm{mM}$. EDA was used in conjunction with the Click-iT ${ }^{\circledR}$ Cell Reaction Buffer Kit (Invitrogen, Carlsbad, CA, USA) and 'clickable' Alexa Fluor 488 Azide (Invitrogen, Carlsbad, CA, USA) per manufacturer's instructions. Overnight bacterial cultures of $B$. anthracis parent strain, $\Delta f t s X$ strain, or $f t s E(K 123 A / D 481 N)$ strain were diluted 1:20 in fresh BHI broth followed by a $1 \mathrm{~h}$ incubation at $37^{\circ} \mathrm{C}$ with shaking at $250 \mathrm{rpm}$. After $1 \mathrm{~h}, 100 \mathrm{mM}$ EDA stock solution was added to the culture to a final concentration of $1 \mathrm{mM}$, and incubation was continued until an $\mathrm{OD}_{600}$ of between 0.6 and 0.65 was reached. The entire culture was centrifuged for $5 \mathrm{~min}$ at $3600 \mathrm{rpm}$ to collect a pellet of the log-phase bacteria. The supernatant was discarded, and a total volume of $5 \mu \mathrm{l}$ of the resulting pellet was placed into $500 \mu \mathrm{l}$ Dulbecco's modified Eagle's medium (DMEM) (Gibco-Invitrogen, Carlsbad, CA, USA) + 10\% fetal bovine serum (FBS) $+1 \mathrm{mM}$ EDA and incubated for $1 \mathrm{~h}$ at $37^{\circ} \mathrm{C}$ in $5 \% \mathrm{CO}_{2}$. After $1 \mathrm{~h}$ incubation with EDA, the bacterial culture was centrifuged for $8 \mathrm{~min}$ at $15,500 \mathrm{rpm}$, and the supernatant was discarded. A $1 \mathrm{ml}$ volume of ice-cold $70 \%$ ethanol was added to the cell pellet and incubated for $1 \mathrm{~h}$ on ice. The ethanol solution was removed and the bacterial cells were resuspended and incubated for $1 \mathrm{~h}$ at room temperature in $1 \mathrm{ml}$ PBS containing 3\% BSA. Cells were then incubated for $1 \mathrm{~h}$ at room temperature in $0.5 \mathrm{ml}$ of Click-iT ${ }^{\circledR}$ Cell Reaction Buffer according to the manufacturer's directions with Alexa Fluor 488 Azide (ThermoFisher Scientific, Waltham, MA, USA) to fluorescently label the EDA incorporated into the cell wall peptidoglycan. The bacterial cells were re-suspended in PBS and placed on glass slides with a coverslip and imaged using a Zeiss LSM 880 confocal microscope (Zeiss, Oberkochem, Germany) using $488 \mathrm{~nm}$ (Alexa Fluor 488) wavelength filter at 63X magnification.

\section{Dual Labeling of Peptidoglycan with EDA and TDL}

TAMRA-D-lysine (TDL) was synthesized according to the protocol described previously (Kuru et al., 2012, 2015). Briefly, 5-carboxytetramethylrhodamine succinimidyl ester (Anaspec, Fremont, CA, USA) and N- $\alpha$-BocD-Lys-OH (Chem-Impex, Bensenville, IL, USA) were mixed to form TDL. The product was purified using reverse phase HPLC on a Waters ZQ 2000 LCMS system (Waters, Milford, MA, USA) with a gradient of acetonitrile in water with $0.1 \%$ (vol/vol) formic acid 5-95\% (vol/vol) acetonitrile for $20 \mathrm{~min}$, eluting at $20 \mathrm{ml} \mathrm{min}{ }^{-1}$. The two isomers were eluted on a Waters Sunfire Prep C18 OBD column with a $5 \mu \mathrm{m}$ particle size, $19 \mathrm{~mm}$ internal diameter and length of $100 \mathrm{~mm}$ (Waters, Milford, MA, USA, product number 186008153). The solution containing the purified product was then lyophilized overnight to form a stable TDL powder, which was stored at $-20^{\circ} \mathrm{C}$ and protected from light.

To perform dual labeling experiments, overnight cultures were diluted 1:20 in fresh BHI broth followed by a $1 \mathrm{~h}$ incubation at $37^{\circ} \mathrm{C}$ with shaking at $250 \mathrm{rpm}$. After $1 \mathrm{~h}, 100 \mathrm{mM}$ EDA stock solution was added to the culture to a final concentration of $1 \mathrm{mM}$, and incubation was continued until an $\mathrm{OD}_{600}$ of between 0.6 and 0.65 was reached. The entire culture was centrifuged for $5 \mathrm{~min}$ at $3600 \mathrm{rpm}$ to collect a pellet of the log-phase bacteria. The supernatant was discarded, and a total volume of $5 \mu \mathrm{l}$ of the resulting pellet was placed into $500 \mu \mathrm{L}$ DMEM (Gibco-Invitrogen, Carlsbad, CA, USA) $+10 \%$ FBS $+1 \mathrm{mM}$ EDA and incubated for $1 \mathrm{~h}$ at $37^{\circ} \mathrm{C}$ in $5 \% \mathrm{CO}_{2}$. After this $1 \mathrm{~h}$ incubation with EDA, the bacterial culture was centrifuged for $8 \mathrm{~min}$ at $15,500 \mathrm{rpm}$, and the supernatant discarded. A total volume of $5 \mu \mathrm{l}$ of the resulting EDA-labeled pellet was placed into $500 \mu \mathrm{l}$ DMEM + $10 \% \mathrm{FBS}+0.5 \mathrm{mM}$ TDL,$-/+$ penicillin $(35 \mu \mathrm{g} / \mathrm{ml})$, tetracycline $(40 \mu \mathrm{g} / \mathrm{ml})$, CXCL10 $(1.4 \mu \mathrm{M})$, or CTTC $(2.8 \mu \mathrm{M})$ and incubated $1 \mathrm{~h}$ at $37^{\circ} \mathrm{C}$ in $5 \% \mathrm{CO}_{2}$. An aliquot of each sample was transferred to individual $1.5 \mathrm{ml}$ Eppendorf tubes and centrifuged for $8 \mathrm{~min}$ at $15,500 \mathrm{rpm}$ after which the supernatant was discarded and the samples were processed and fixed for imaging as described above.

The bacterial cells were re-suspended in PBS and placed on glass slides with a coverslip and imaged using a Zeiss LSM 880 confocal microscope (Zeiss, Oberkochem, Germany) using $488 \mathrm{~nm}$ (Alexa Fluor 488) and $514 \mathrm{~nm}$ (TDL) wavelength filters at 63X magnification. Phase contrast light microscopy images 
and fluorescence images were collected using settings, including brightness and contrast, which were optimized and fixed based on the corresponding untreated control group at the beginning of the acquisition session. Further analyses were completed using Image J (Schneider et al., 2012). Relative fluorescent intensity was calculated as a percent control of the untreated sample. Ten individual fields per experimental run were analyzed to determine mean fluorescence intensity $+/-$ standard deviation, as compared to results for untreated control sample of the same strain. Control and test samples were not compared between runs to account for experimental variation in the percent control determination.

\section{Peptidoglycan Release Assay}

Overnight cultures were diluted 1:20 in fresh BHI broth followed by a $2 \mathrm{~h}$ incubation at $37^{\circ} \mathrm{C}$ with shaking at $250 \mathrm{rpm}$. Vegetative cells were diluted to approximately $5.0 \times 10^{6} \mathrm{CFU} \mathrm{ml} \mathrm{m}^{-1}$ in fresh DMEM with high glucose, no glutamine, no phenol red (Gibco-Invitrogen, Carlsbad, CA, USA) that also contained $4 \mathrm{mM}$ GlutaMAX $^{\mathrm{TM}}$ supplement, 10\% (v/v) FBS (HyClone, Logan, UT, USA), and the concentration of penicillin, CXCL10, or CTTC to be tested. Aliquots of $400 \mu \mathrm{l}$ were placed into 48 well plates and incubated at $37^{\circ} \mathrm{C}$ with $5 \% \mathrm{CO}_{2}$ for 0 or $2 \mathrm{~h}$. Penicillin $\left(0.5 \mu \mathrm{g} \mathrm{ml}^{-1}\right)$ was used as a positive control. CXCL10 was tested at a concentration of $1.4 \mu \mathrm{M}$, and CTTC was tested at $2.8 \mu \mathrm{M}$. At time $0 \mathrm{~h}$ or after a $2 \mathrm{~h}$ incubation, the supernatants for each sample group were collected and transferred into $1.5 \mathrm{ml}$ Eppendorf tubes and centrifuged for $5 \mathrm{~min}$ at $15,000 \mathrm{rpm}$. The resulting supernatant was sterilized by filtration through a $13 \mathrm{~mm} 0.22 \mu \mathrm{M}$ filter (ThermoFisher Scientific, Waltham, MA, USA) and then heat-inactivated for $5 \mathrm{~min}$ at $95^{\circ} \mathrm{C}$. Concurrent CFU ml measurements were determined for each sample. The HEK-Blue ${ }^{\mathrm{TM}}$ hNOD2 mammalian cells (Invivogen, San Diego, CA, USA) were grown and maintained in DMEM medium containing $10 \% \mathrm{FBS}, 50 \mathrm{U} / \mathrm{ml}$ penicillin, $50 \mu \mathrm{g} / \mathrm{ml}$ streptomycin, $100 \mu \mathrm{g} / \mathrm{ml}$ Normocin, $30 \mu \mathrm{g} / \mathrm{ml}$ blasticidin, and $100 \mu \mathrm{g} / \mathrm{ml}$ Zeocin at $37^{\circ} \mathrm{C}$ with $5 \% \mathrm{CO}_{2}$ for up to no more than 10 passages and used as per manufacturer's instructions. Briefly, the cells were sub-cultured into 96-well plates at a concentration of 50,000 cells well $^{-1}$ in $180 \mu \mathrm{l}$ total volume and were incubated with $20 \mu \mathrm{l}$ of the filtered supernatant in triplicate for $20 \mathrm{~h}$ at $37^{\circ} \mathrm{C}$ with $5 \% \mathrm{CO}_{2}$. Finally, $20 \mu \mathrm{l}$ of the resulting HEK-Blue $\mathrm{TM}^{\mathrm{TM}}$ hNOD2 supernatant was added to $180 \mu \mathrm{l} \mathrm{HEK}-$ Blue $^{\mathrm{TM}}$ detection medium (Invivogen, San Diego, CA, USA) and incubated for $24 \mathrm{~h}$ at $37^{\circ} \mathrm{C}$ with $5 \% \mathrm{CO}_{2}$. Muramyl dipeptide (MDP) (Invivogen, San Diego, CA, USA) at a final concentration of $15 \mathrm{ng} / \mathrm{ml}$ reconstituted as a stock solution of $0.1 \mathrm{mg} / \mathrm{ml}$ in pure $\mathrm{H}_{2} \mathrm{O}$ was used as a positive control. Filtered DMEM was used as a medium control and pure $\mathrm{H}_{2} \mathrm{O}$ was used as a second negative control. The colorimetric change of the detection medium [due to secreted embryonic alkaline phosphatase (SEAP) enzyme released upon NF- $\kappa \mathrm{B}$ reporter system activation] was measured at $\mathrm{OD}_{650}$ using an ELx800 Absorbance Reader (BioTek, Winooski, VT, USA).

\section{Statistical Analyses}

Statistical analyses were performed using GraphPad Prism 6.0 software. Experimental groups were analyzed using an unpaired, two-tailed Student's $t$-test or Mann-Whitney test as noted in the text or figure legends. Significant differences were determined to have a $p$-value of $\leq 0.05$.

\section{RESULTS}

\section{B. anthracis $\Delta f t s X$ and ftsE(K123A/D481N) Exhibited Significant Morphological Differences Compared to the Parent Strain}

Previous studies with $B$. anthracis $\Delta f t s X$ and $f t s E(K 123 A / D 481 N)$ showed that they have about a $30 \mathrm{~min}$ lag phase prior to initiation of $\log$ phase growth in BHI broth media compared to the parent strain (Crawford et al., 2011; Margulieux et al., 2016). However, their growth rates were similar once log phase was achieved, so all of the following experiments were conducted with mid-log phase cultures. All B. anthracis strains used in this study exhibited marked incorporation of EDA into the septa after $2 \mathrm{~h}$ of incubation, indicative of active cellular division. EDA incorporation was also noted along the cell wall of each vegetative cell, suggesting that the modified D-alanine was incorporated into the cell wall of the growing/dividing bacteria (Figure 1A). Notably, significant morphological differences in cell length, cell width, number of septa in a given distance, and bacterial chain angle were observed between the $B$. anthracis parent strain and the $\Delta f t s X$ and $f t s E(K 123 A / D 481 N)$ strains (Figures 1A-E). In our present study, $B$. anthracis parent strain appeared as regular, even, and smooth chains of vegetative cells while the mutant strains showed a "kinked" phenotype (Figure 1A). Cells of B. anthracis $\Delta f t s X$ and $f t s E(K 123 A / D 481 N)$ were significantly shorter in length (measured as the septum-to-septum distance of bacterial cells in a chain) and wider (measured as the width across the midpoint of the cell) compared to the parent strain (Figures 1B,C). These morphological differences were consistent with results reported for Bacillus subtilis mutants of the FtsE/X complex (Garti-Levi et al., 2008; DomínguezCuevas et al., 2013; Meisner et al., 2013). B. anthracis $\Delta f t s X$ and $f t s E(K 123 A / D 481 N)$ also exhibited an increased number of septal division points over the arbitrarily chosen distance of $10 \mu \mathrm{m}$, which suggested an altered or dysregulated process of cellular division and/or elongation in these mutants (Figures 1A,D). The "kinked" morphology, noted above, was quantified through measurement of vegetative cell chain angles from end-middleend of the entire chain. These measurements indicated that, compared to the $B$. anthracis parent strain, the B. anthracis $\Delta f t s X$ and $f t s E(K 123 A / D 481 N)$ mutant strains exhibited a wide array of more acute angles within chains of bacteria (Figure 1E).

\section{Effects of CXCL10 and CTTC on Existing Peptidoglycan Integrity and New Incorporation of Peptidoglycan Precursors in B. anthracis Parent Strain}

In order to examine if the antimicrobial effect of CXCL10 and CTTC against vegetative cells of $B$. anthracis was due to an alteration of peptidoglycan integrity and/or inhibition 
A

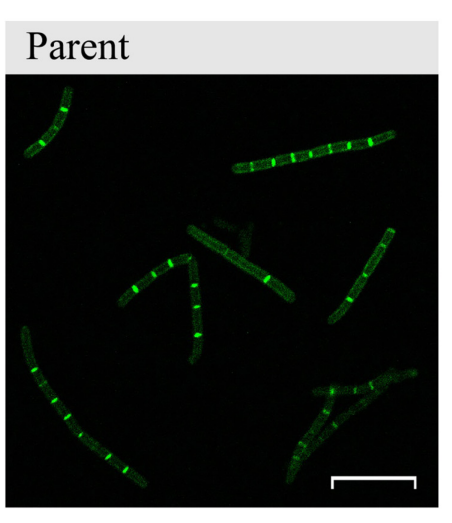

B

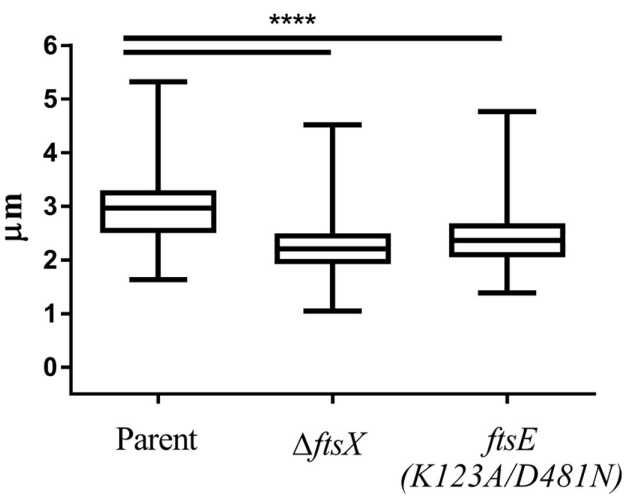

Septa Over $10 \mu \mathrm{m}$

D

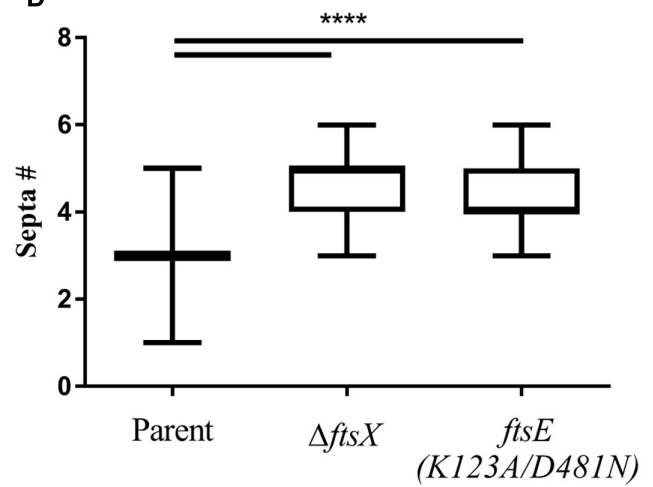

\section{$\Delta f t s X$}

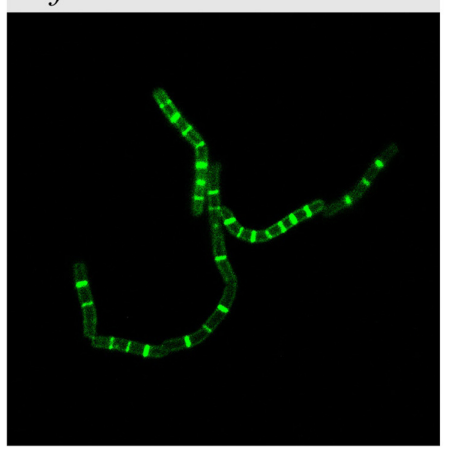

C

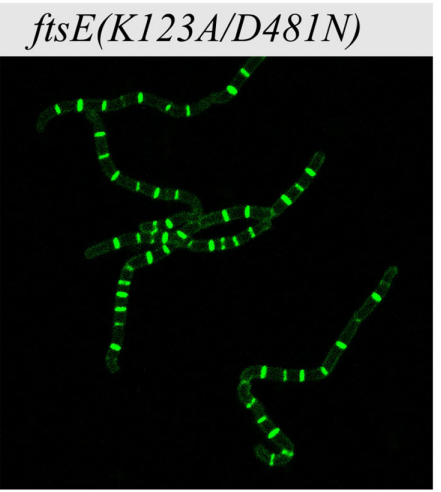

Cell Width

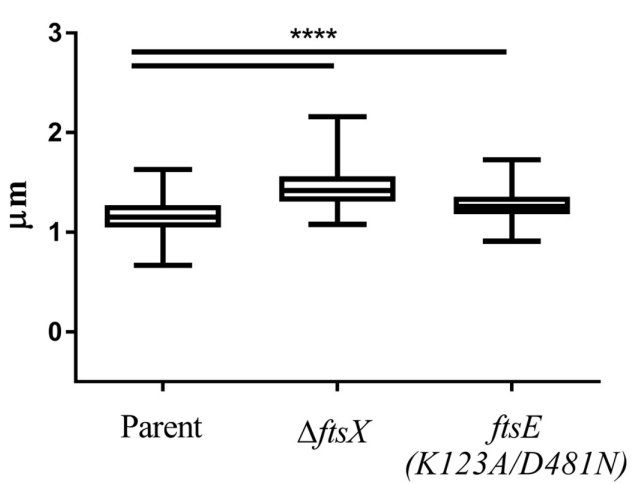

Chain Angle

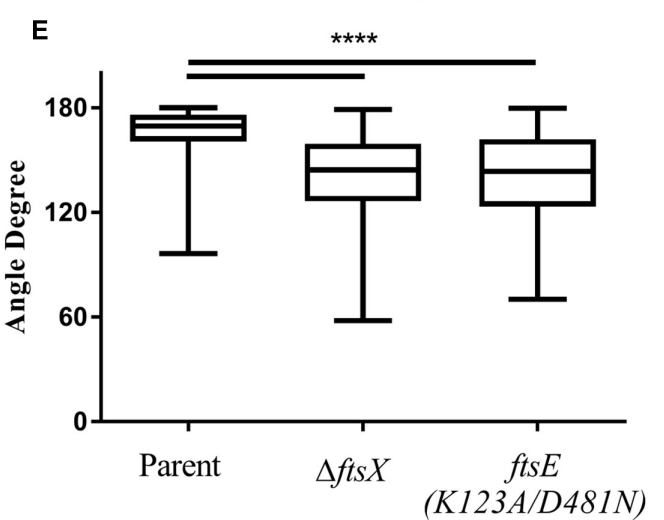

FIGURE 1 | Quantification of Bacillus anthracis parent strain, $\Delta \mathrm{fts} X$, or ftsE(K123A/D481N) vegetative cell morphological features of cell length, width, number of septa in a given distance, and angles formed by bacterial chains. (A) $B$. anthracis parent strain, $B$. anthracis $\Delta$ fts $X$ strain, and $B$. anthracis $\mathrm{ftsE}($ K123A/D481N) strain visualization of incorporated EDA after "Click-iT" reaction using Alexa Fluor 488 azide. Comparison of (B) individual cell length, measured as the distance from a septum to an adjacent septum in a bacterial chain, (C) individual cell width, measured at the midpoint of the bacterial rod, (D) total number of septa in a bacterial chain, measured over an arbitrarily chosen distance of $10 \mu \mathrm{m}$, and (E) chain angle, as measured from end-middle-end of a chain of bacterial cells. Confocal microscopy images of untreated B. anthracis parent, $\Delta \mathrm{fts} X$, and ftsE(K123A/D481N) strains are shown as EDA+Alexa Fluor 488 green fluorescence images at 63X magnification. Scale bar represents $10 \mu \mathrm{m}$. Images are representative of $n=3$ separate experiments with 10-20 images per experiment acquired per strain. Comparisons were made between $B$. anthracis parent strain, $\Delta f t s X$, and ftsE(K123A/D481N). Measurements of individual vegetative cells and bacterial chains were determined using Image J (Schneider et al., 2012). A total of 100 measurements was collected each for bacterial length and width for a given strain and condition per experiment. A total of 50 measurements was collected for determining the number of septa in an arbitrarily chosen distance of $10 \mu \mathrm{m}$ and for chain angle determination for each strain and condition per experiment. Results are represented as a box-and-whisker plot with data points represented from minimum to maximum; $n=3$ separate experiments from which data was collected. Data were analyzed using a Mann-Whitney test, **** $p<0.0001$. 


\section{B. anthracis Parent Strain}

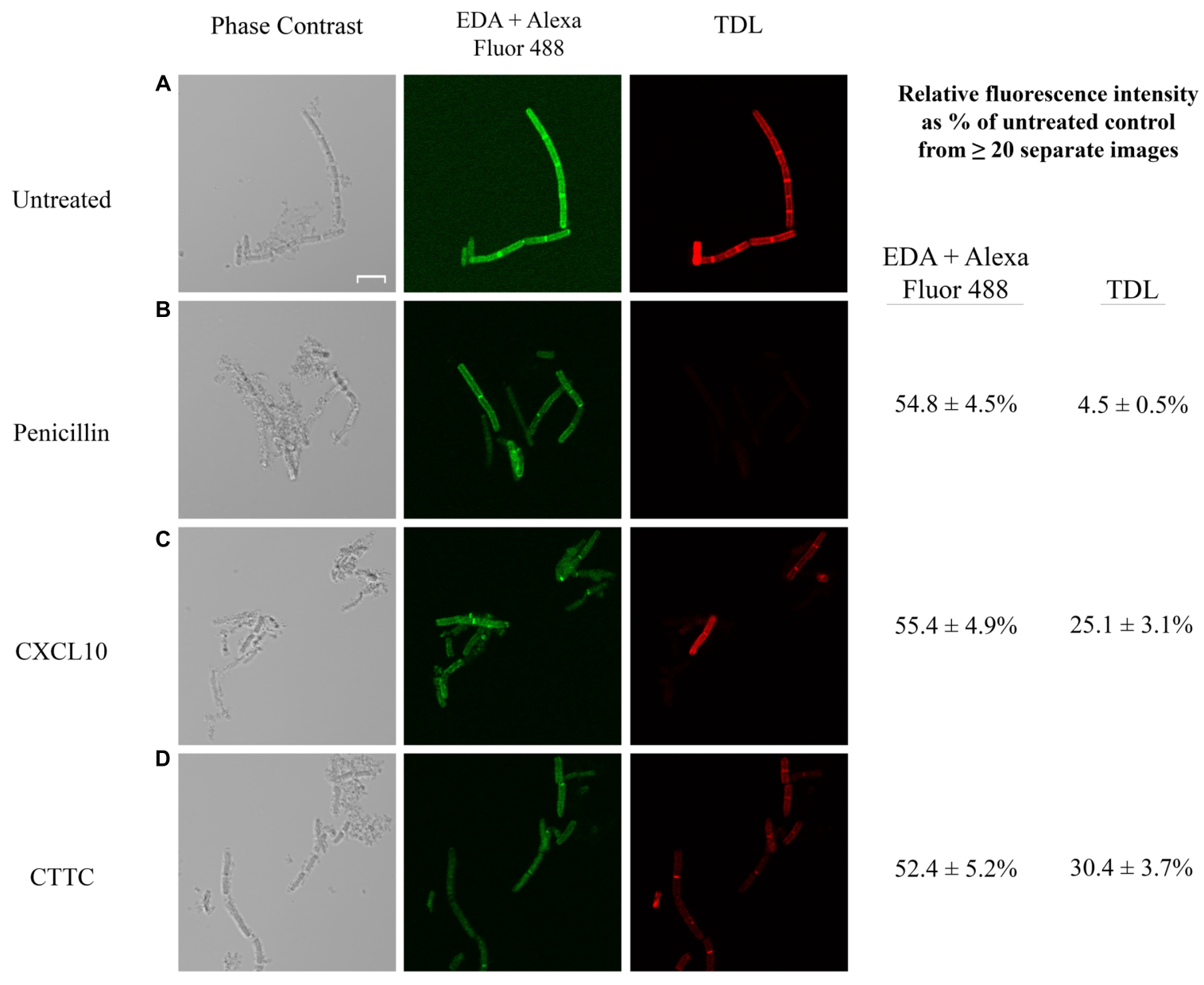

FIGURE 2 | Effects of various antimicrobial agents on the peptidoglycan of $\boldsymbol{B}$. anthracis parent strain. B. anthracis parent strain was treated with (A) buffer control, (B) penicillin (35 $\mathrm{g} / \mathrm{ml}),(\mathbf{C})$ CXCL10 (2.8 $\mu \mathrm{M})$, or (D) CTTC $(2.8 \mu \mathrm{M})$ to determine the effect on existing peptidoglycan integrity (EDA + Alexa Fluor 488 green fluorescence) and new subunit incorporation (TDL red fluorescence). Vegetative cells were incubated with EDA for $1 \mathrm{~h}$ before the addition of an antimicrobial agent (or buffer control) concurrently with TDL for $1 \mathrm{~h}$, followed by a "Click-iT" reaction to bind Alexa Fluor 488 to EDA, as described in Section "Materials and Methods." Scale bar is $5 \mu \mathrm{m} . n=2$ separate experiments with 5-20 images being acquired for each treatment group in each experiment. Relative fluorescence intensity was determined as a percentage of the untreated control sample of the same strain.

of new synthesis, we performed dual labeling experiments using EDA and TDL as described in Section "Materials and Methods" to determine if there was a difference in peptidoglycan remodeling. Dual labeling allowed us to determine effects on existing peptidoglycan (EDA-labeled) and new peptidoglycan subunit incorporation (TDL-labeled) in the absence or presence of CXCL10, CTTC, or other antimicrobial agents. We used an untreated sample to standardize the baseline microscopy settings for the treated samples. Images of the untreated and treated sample groups for one bacterial strain were obtained in one session to ensure comparative fluorescent levels. The sequential incorporation of EDA and TDL into the septa of vegetative cells was observed with the untreated parent strain (Figure 2A). Penicillin was used as a positive control as it is a beta-lactam antibiotic that targets the bacterial cell wall and blocks the final cross-linking step, resulting in a loss of peptidoglycan integrity and cell lysis (Figure 2B) (Tipper and Strominger, 1965; Wise and Park, 1965; Novak et al., 2000). Tetracycline was used as a negative control as it is a bacteriostatic agent that inhibits protein synthesis by targeting the bacterial aminoacyl-tRNAs and 30S ribosome complex (Chopra and Roberts, 2001). In the presence of penicillin $(35 \mu \mathrm{g} / \mathrm{ml})$, the parent strain exhibited reduced fluorescence signal from previously incorporated EDA $(54.8 \pm 4.5 \%$ of untreated control) and an absence $(4.5 \pm 0.5 \%$ of untreated control) of newly incorporated TDL-labeled peptidoglycan subunits (Figure 2B). In contrast, incubation of $B$. anthracis parent strain with tetracycline $(40 \mu \mathrm{g} / \mathrm{ml})$ had a lesser impact on the incorporation of both EDA $(71.0+3.4 \%$ of 
untreated control) and TDL (54.7 $\pm 3.6 \%$ of untreated control) into the peptidoglycan (data not shown), which likely reflected that this bacteriostatic drug inhibited bacterial growth during the incubation period. In the presence of CXCL10 $(1.4 \mu \mathrm{M})$, the $B$. anthracis parent strain exhibited decreased levels of EDA-labeled peptidoglycan $(55.4 \pm 4.9 \%$ of untreated control) and reduced levels of TDL-labeled peptidoglycan $(25.1 \pm 3.1 \%$ of untreated control) (Figure 2C). Incubation of $B$. anthracis parent strain with CTTC $(2.8 \mu \mathrm{M})$ resulted in a similar loss of EDA and TDL fluorescence, $52.4 \pm 5.2 \%$ and $30.4 \pm 3.7 \%$ of untreated control, respectively (Figure 2D).

\section{Effects of CXCL10 and CTTC on Peptidoglycan Turnover/Synthesis of $B$. anthracis $\Delta$ fts $X$ and ftsE(K123A/D481N)}

Bacillus anthracis $\Delta f t s X$ is less susceptible to CXCL10 than the parent strain and is completely resistant to CTTC (Margulieux et al., 2016). Killing of the $B$. anthracis $\Delta f t s X$ strain by higher concentrations of CXCL10 appears to occur by an FtsE/Xindependent pathway through general membrane depolarization and disruption via the C-terminal amphipathic $\alpha$-helix of CXCL10 (Margulieux et al., 2016). The data obtained with the $B$. anthracis parent strain indicates that CXCL10 impacts peptidoglycan processing via the FtsE/X-dependent pathway; however, the $B$. anthracis $\Delta f t s X$ mutant lacks the FtsX target necessary for interaction with CXCL10. Thus, the only pathway by which CXCL10 can exert its effect is the previously described FtsE/X-independent mechanism that results in cellular lysis through generalized membrane depolarization. The $B$. anthracis $\Delta f t s X$ untreated control strain incorporated both EDA and TDL into the peptidoglycan (Figure 3A). Penicillin treatment resulted in an absence of TDL incorporation $(6.3 \pm 1.0 \%$ of untreated control), i.e., newly synthesized peptidoglycan (Figure 3B). Notably, the EDA fluorescence $(93.4 \pm 10.3 \%$ of untreated control) was unaffected by penicillin treatment compared to the penicillin-treated parent strain (Figure 2B), which suggested a possible difference between these strains to the effects of penicillin. B. anthracis $\Delta f t s X$ incubation with tetracycline gave similar results to those observed with the parent strain (data not shown). Incubation of $B$. anthracis $\Delta f t s X$ with CXCL10 resulted in CXCL10 having only a minor effect on the integrity of the existing (pre-treatment) peptidoglycan based on the fluorescence intensity due to $\operatorname{EDA}(89.5 \pm 6.6 \%$ of untreated control $)$ and an intermediate effect on newly synthesized peptidoglycan based on reduction in TDL signal intensity $(44.0 \pm 3.8 \%$ of untreated control) (Figure 3C). Under light microscopy, vegetative cells of $\Delta f t s X$ exhibited some cell lysis, perhaps due to membrane depolarization and cell death via the FtsX-independent pathway, which may have had some effect on fluorescence intensity compared to the untreated $\Delta f t s X$ control. CTTC treatment had no impact on EDA ( $116.8 \pm 7.2 \%$ of untreated control) or TDL $(101.4 \pm 6.3 \%$ of untreated control) incorporation/uptake into the peptidoglycan of $B$. anthracis $\Delta f t s X$ (Figure 3D). These data suggested that in the absence of FtsX, the $\mathrm{N}$-terminal region of
CXCL10 was not able to initiate a bactericidal effect through disruption of peptidoglycan integrity or synthesis.

An FtsE mutant $f t s E(K 123 A / D 481 N)$ was previously constructed in which select point mutations in the Walker sites eliminated ATP hydrolysis rendering the FtsE/X complex functionally inactive (Margulieux et al., 2016). Like $\Delta f t s X$, the $B$. anthracis $f t s E(K 123 A / D 481 N)$ mutant strain was also found to be less susceptible to CXCL10 and completely resistant to CTTC (Margulieux et al., 2016). Dual labeling of untreated B. anthracis $f t s E(K 123 A / D 481 N)$ yielded similar results for EDA and TDL incorporation (Figure 4A) as observed with $B$. anthracis $\Delta f t s X$ (Figure 3A). Incubation of $f t s E(K 123 A / D 481 N)$ with penicillin resulted in no loss of EDA relative fluorescence intensity (102.8 $\pm 7.1 \%$ of untreated control), but a significant reduction in newly synthesized peptidoglycan as evidenced by reduced incorporation of TDL $(7.9 \pm 1.2 \%$ of untreated control) (Figure 4B). Tetracycline treatment of the $B$. anthracis $f t s E(K 123 A / D 481 N)$ strain gave results that were similar to those obtained with $\Delta f t s X$ (data not shown). CXCL10 had little effect on the incorporation of EDA in $f t s E(K 123 A / D 481 N)$, while TDL incorporation ( $48.4 \pm 5.3 \%$ of control) in this mutant strain (Figure 4C) was similar to the results for $\Delta f t s X$ (Figure 3C). Similar to the findings for the $\Delta f t s X$ strain in Figure 3, CTTC treatment of the $f t s E(K 123 A / D 481 N)$ mutant strain had no apparent impact on existing peptidoglycan integrity as measured by EDA incorporation ( $97.5 \pm 3.9 \%$ of untreated control) or on newly synthesized peptidoglycan as measured by TDL incorporation (106.3 $\pm 8.0 \%$ of untreated control) (Figure 4D).

\section{CXCL10 and CTTC Increased Peptidoglycan Release in B. anthracis Parent Strain}

A mammalian reporter cell line that overexpressed the immune cell receptor NOD2 was used to quantitate the amount of peptidoglycan released (Packiam et al., 2015; Liechti et al., 2016). This assay provided a sensitive method for quantitating the amount of peptidoglycan released by bacteria exposed to antimicrobial agents (Girardin et al., 2003a,b; Loving et al., 2009; Philpott et al., 2014; Packiam et al., 2015). The NOD2 receptors expressed by the reporter cell line are activated by binding fragments containing $\mathrm{N}$-acetylmuramic acid released from bacterial cell walls (Girardin et al., 2003a,b). The activated NOD2 receptor subsequently activates an NF- $\mathrm{B}$ construct in the mammalian cell that results in the production of a SEAP reporter (Packiam et al., 2015; Liechti et al., 2016). SEAP activity causes a colorimetric change to the detection medium such that the enzymatic activity of SEAP is proportional to the amount of MDP in the original sample. An antibiotic that targets the cell wall (penicillin) was used as a positive control in this study. Tetracycline was used as a negative control. The parent strain exhibited a significant increase in peptidoglycan release, as compared to the untreated parent strain control, when exposed to penicillin $(0.5 \mu \mathrm{g} / \mathrm{ml})$, CXCL10 $(1.4 \mu \mathrm{M})$, or CTTC $(2.8 \mu \mathrm{M})$ (Figure 5A). In contrast, no increase in the release of peptidoglycan was observed after incubation with tetracycline $(10 \mu \mathrm{g} / \mathrm{ml})$ (data not shown). With the B. anthracis $\Delta f t s X$ strain, 


\section{B. anthracis $\Delta f t s X$ Strain}

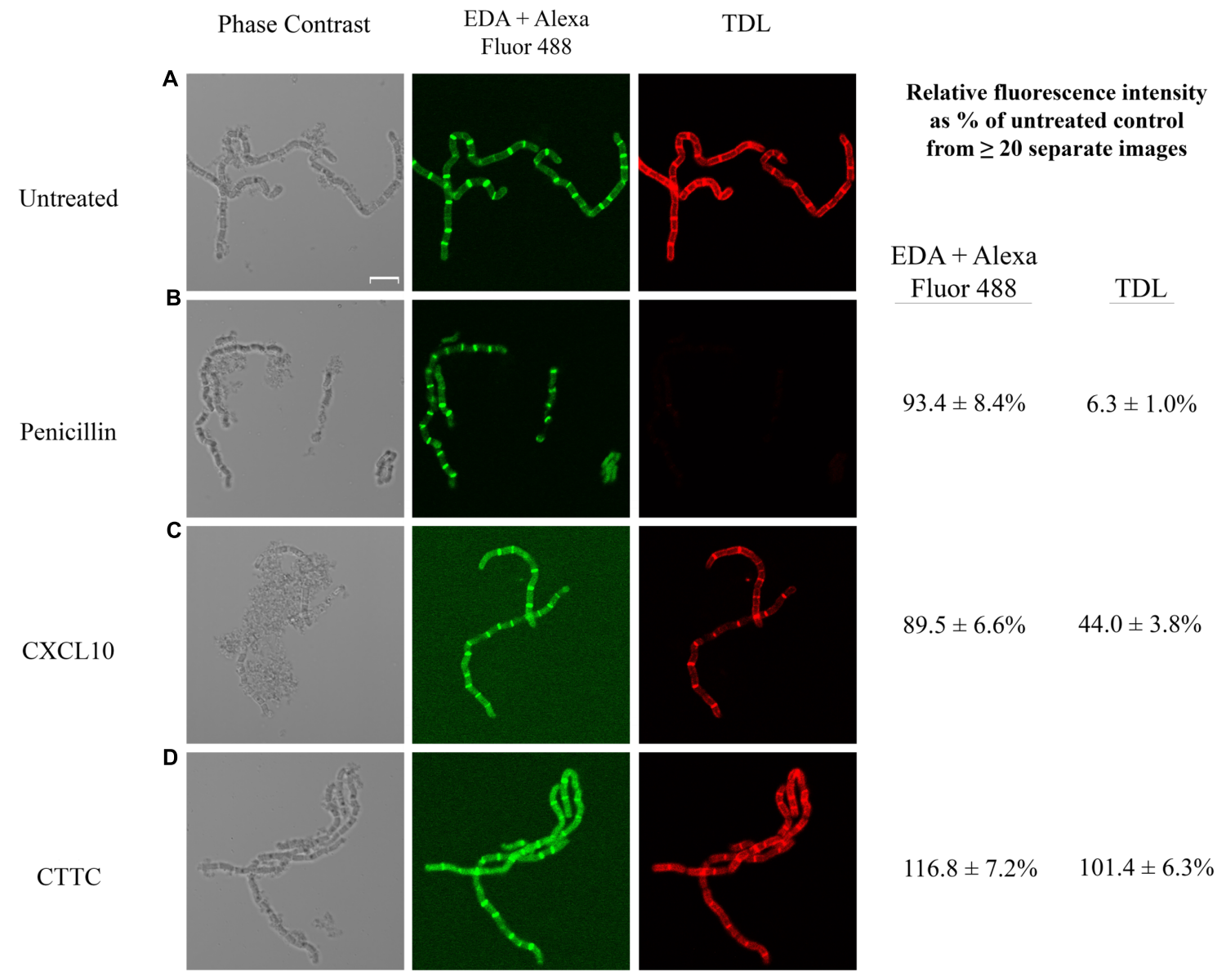

FIGURE 3 | Effects of various antimicrobial agents on the peptidoglycan of $\boldsymbol{B}$. anthracis $\boldsymbol{\Delta}$ fts $\boldsymbol{X}$. B. anthracis $\Delta$ fts $X$ strain was treated with (A) buffer control, (B) penicillin $(35 \mu \mathrm{g} / \mathrm{ml})$, (C) CXCL10 $(2.8 \mu \mathrm{M})$, or (D) CTTC $(2.8 \mu \mathrm{M})$ to determine the effect on existing peptidoglycan integrity (EDA + Alexa Fluor 488 green fluorescence) and new subunit incorporation (TDL red fluorescence). Vegetative cells were incubated with EDA for $1 \mathrm{~h}$ before the addition of an antimicrobial agent (or buffer control) concurrently with TDL for 1 h, followed by a "Click-iT" reaction to bind Alexa Fluor 488 to EDA, as described in Section "Materials and Methods." Scale bar is $5 \mu \mathrm{m} . n=2$ separate experiments with 5-20 images being acquired for each treatment group in each experiment. Relative fluorescence intensity was determined as a percentage of the untreated control sample of the same strain.

a statistically significant increase in peptidoglycan release was observed in the presence of penicillin or CXCL10 (Figure 5B). However, no increase in peptidoglycan release by $\Delta f t s X$ was observed in the presence of CTTC, suggesting that CTTC did not disrupt peptidoglycan processing. Corresponding viable bacterial cell counts (colony forming units [CFU] per $\mathrm{ml}$ ) were also obtained for both the parent and $\Delta f t s X$ strains to quantitate the degree of bacterial killing under these experimental conditions (Figures 5C,D). Upon exposure to CXCL10, only $0.02 \%$ of the parent strain cells remained viable after $1 \mathrm{~h}$ while $70 \%$ of the cells in the presence of CTTC remained viable compared to the initial inoculum concentration of bacteria. Comparatively, CXCL10- or CTTC-treated samples of $\Delta f t s X$ were able to grow such that the $\mathrm{CFU} / \mathrm{ml}$ results matched or exceeded those of the initial bacterial inoculum for the strain.

\section{DISCUSSION}

The FtsE/X-dependent pathway by which CXCL10 kills $B$. anthracis has been shown to be mediated through the N-terminal region(s) of CXCL10, independent of the amphipathic $\alpha$-helix, but the exact mechanism of action has remained unknown. Confocal microscopy studies using fluorescence labeling of peptidoglycan amino acid components revealed that CXCL10 and CTTC caused a loss, or release, of existing peptidoglycan and decreased the incorporation of new subunits into the peptidoglycan of $B$. anthracis parent strain. The mechanism of peptidoglycan disruption by CXCL10 and CTTC appears to be distinct from that of penicillin, which was used in our studies as a cell wall active antimicrobial control. The effect of penicillin, CXCL10, and CTTC on existing peptidoglycan 


\section{B. anthracis ftsE(K123A/D481N) Strain}

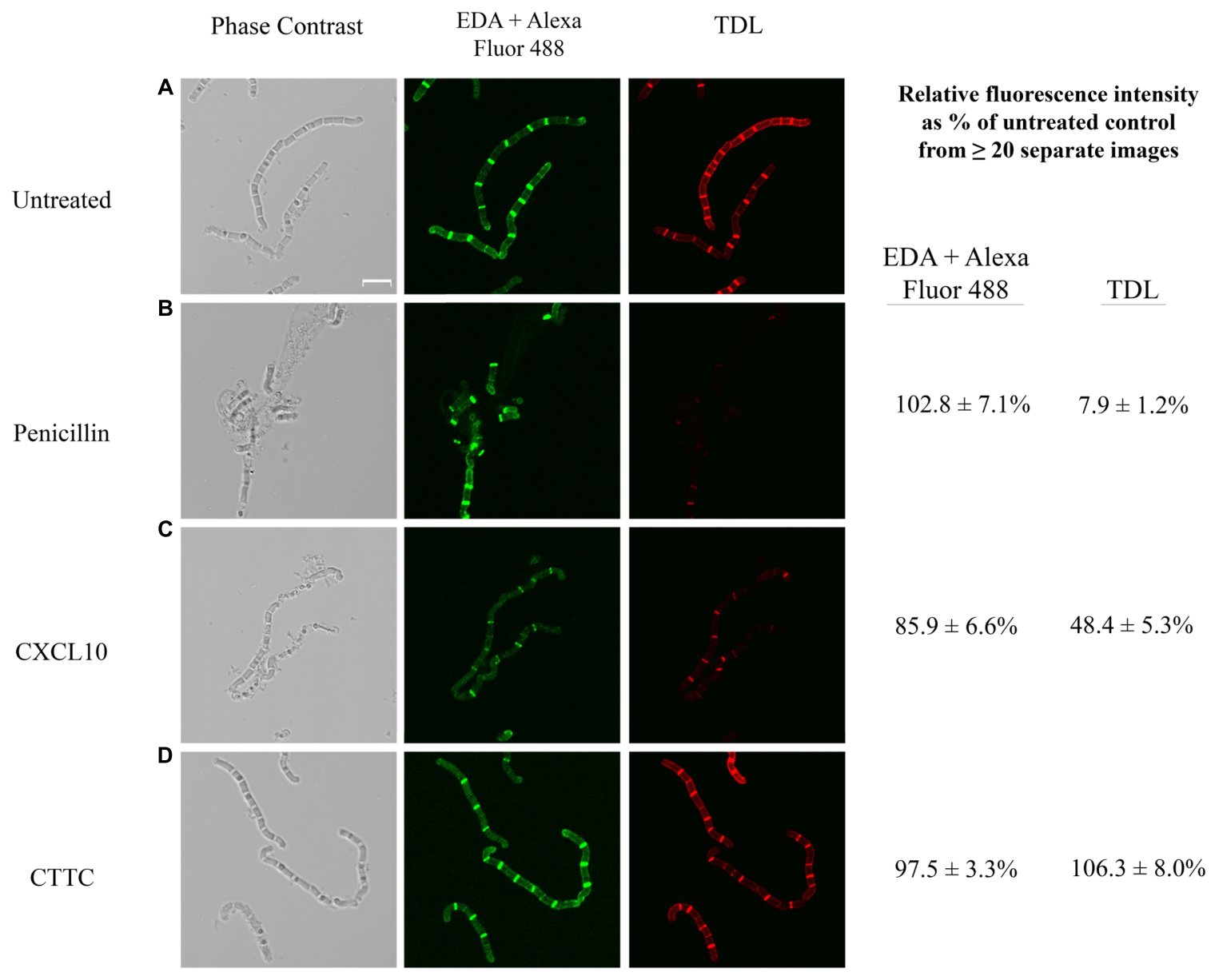

FIGURE 4 | Effects of various antimicrobial agents on the peptidoglycan of B. anthracis ftsE(K123A/D481N). B. anthracis ftsE(K123A/D481N) strain was treated with (A) buffer control, (B) penicillin (35 $\mathrm{g} / \mathrm{ml})$, (C) CXCL10 $(2.8 \mu \mathrm{M})$, or (D) CTTC $(2.8 \mu \mathrm{M})$ to determine the effect on existing peptidoglycan integrity (EDA + Alexa Fluor 488 green fluorescence) and new subunit incorporation (TDL red fluorescence). Vegetative cells were incubated with EDA for $1 \mathrm{~h}$ before the addition of an antimicrobial agent (or buffer control) concurrently with TDL for $1 \mathrm{~h}$, followed by a "Click-iT" reaction to bind Alexa Fluor 488 to EDA, as described in Section

"Materials and Methods." Scale bar is $5 \mu \mathrm{m} . n=2$ separate experiments with 5-20 images being acquired for each treatment group. Relative fluorescence intensity was determined as a percentage of the untreated control sample of the same strain.

(EDA-labeled) was similar in all strains tested, including a similar reduction in relative fluorescence intensity from existing peptidoglycan in the $B$. anthracis parent strain that was abrogated in the $\Delta f t s X$ and $f t s E(K 123 A / D 481 N)$ mutant strains. In contrast, penicillin blocked essentially all incorporation of newly synthesized peptidoglycan (TDL fluorescence) in each of the three strains tested, while CXCL10 and CTTC only markedly blocked TDL incorporation in the B. anthracis parent strain. The absence of a functional FtsE/X complex in the B. anthracis $\Delta \mathrm{fts} X$ and $f t s E(K 123 A / D 481 N)$ mutant strains rendered CXCL10 or CTTC less effective, or completely ineffective, in inhibiting the incorporation of newly synthesized peptidoglycan.

Thus, it appears that CXCL10 and CTTC have an impact on the integrity of existing peptidoglycan and an effect on incorporation of newly synthesized peptidoglycan that is dependent on the presence of a functional FtsE/X complex. It should be noted that, in the presence of full-length CXCL10, both of the mutant strains still appeared to undergo some lysis, which was expected since CXCL10 appears to be a bifunctional antimicrobial agent that is also capable of killing $B$. anthracis through an FtsX-independent pathway (Margulieux et al., 2016). The CTTC protein, which lacks the CXCL10 amphipathic C-terminal $\alpha$-helix, had no effect on peptidoglycan processing in both $\Delta f t s X$ and $f t s E(K 123 A / D 481 N)$ mutant strains, supporting the hypothesis that a functional FtsE/X complex is required to mediate the activity of CXCL10. These observations were confirmed by measuring peptidoglycan release, which revealed that CTTC caused a release of peptidoglycan from the 


\section{B. anthracis parent}
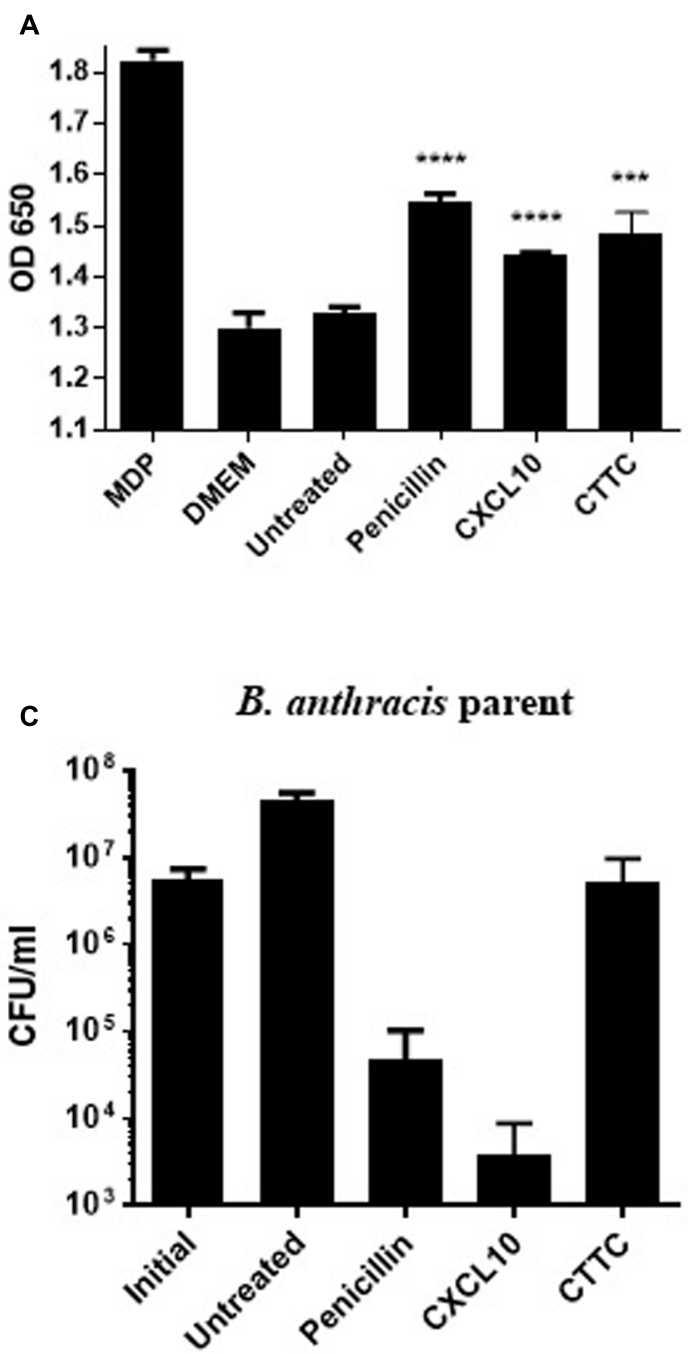

B. anthracis $\Delta f t \mathrm{~s} X$

B

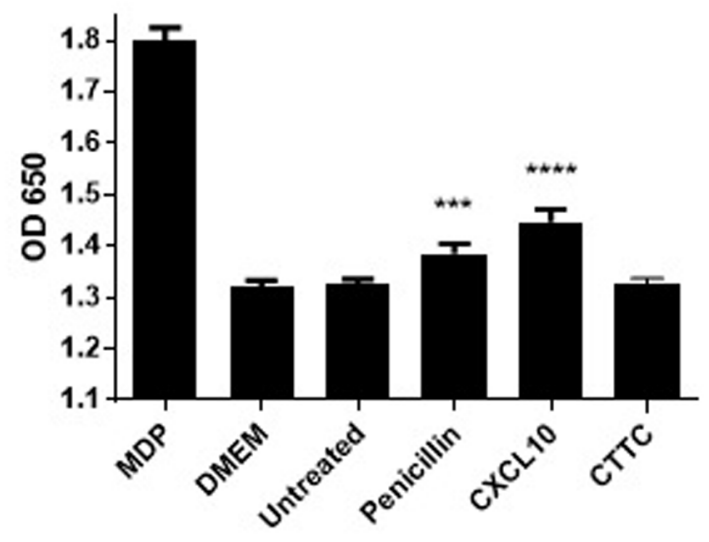

D B. anthracis $\Delta f t s X$

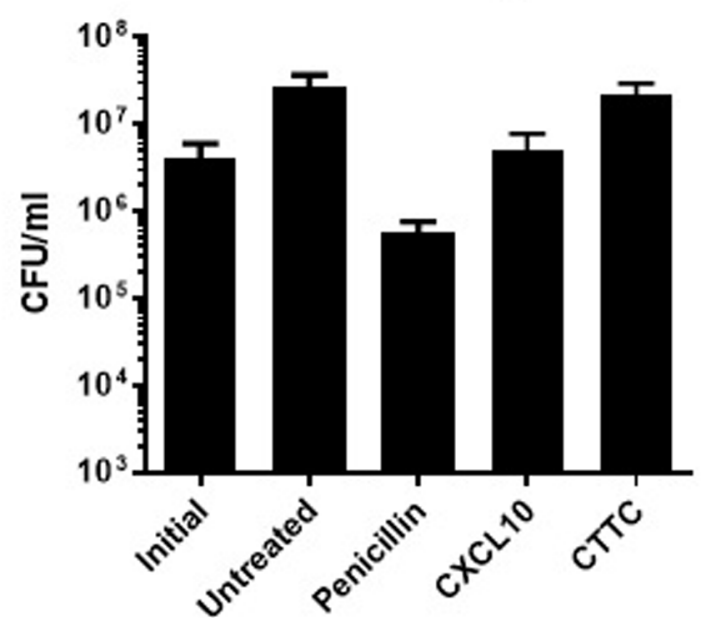

FIGURE 5 | Detection of peptidoglycan release using HEK cells that express a NOD2-NF- $\mathrm{B}$ reporter system with concurrent CFU data collection. Peptidoglycan subunit release into the supernatant of untreated or antimicrobial-treated vegetative cells was detected by an HEK-Blue ${ }^{T M}$ hNOD2 mammalian cell line that expresses the NOD2 receptor, which detects bacterial peptidoglycan and activates an NF-кB reporter system that produces a SEAP enzyme for a colorimetric-based quantitative readout. (A) Detection of $B$. anthracis parent strain peptidoglycan release in response to penicillin (0.5 $\mu \mathrm{g} / \mathrm{ml})$, $\mathrm{CXCL} 10$ (1.4 $\mu \mathrm{M})$, or CTTC $(2.8 \mu \mathrm{M})$, as compared to the untreated control group of the same bacterial strain. (B) Detection of $B$. anthracis $\Delta$ fts $X$ peptidoglycan release in response to penicillin $(0.5 \mu \mathrm{g} / \mathrm{ml})$, CXCL10 $(1.4 \mu \mathrm{M})$, or CTTC $(2.8 \mu \mathrm{M})$, as compared to the untreated control group of the same bacterial strain. CFU enumeration was performed at the $2 \mathrm{~h}$ time point in parallel with supernatant collection and peptidoglycan release assay. These corresponding CFU data are shown for

(C) B. anthracis parent strain or (D) B. anthracis $\Delta$ fts X exposed to penicillin $(0.5 \mu \mathrm{g} / \mathrm{ml})$, CXCL10 (1.4 $\mu \mathrm{M})$, or CTTC (2.8 $\mu \mathrm{M})$. Results are represented $\pm \mathrm{SEM}, n=3$ separate experiments with triplicate wells used in each experiment. ${ }^{* * *} p \leq 0.0001,{ }^{* * * *} p<0.0001$.

B. anthracis parent strain but was unable to cause any significant increase in release of peptidoglycan from the $B$. anthracis $\Delta f t s X$ mutant strain. These results support the hypothesis that FtsE/X-dependent killing by CXCL10 requires a functional FtsE/X complex and results from disruption of peptidoglycan processing.

Peptidoglycan determines cell shape and provides the structural integrity required to withstand changes in osmotic pressure (Reith and Mayer, 2011; Turner et al., 2014).
Remodeling of the peptidoglycan is a vital process during all stages of the bacterial life cycle and is tightly regulated for optimal turnover and cell growth (Reith and Mayer, 2011; Lovering et al., 2012; Turner et al., 2014). The FtsE/X complex has been found to be widely conserved among Gram-positive, Gram-negative, and acid fast bacteria, and is thought to be part of a large cell wall synthesis complex that is responsible for peptidoglycan remodeling (Schmidt et al., 2004; Garti-Levi et al., 2008; Domínguez-Cuevas et al., 2013; Meisner et al., 2013; 
Sham et al., 2013; Bartual et al., 2014; Mavrici et al., 2014; Mir et al., 2015; Bajaj et al., 2016). Other groups have found that the FtsE/X complex in the Gram-positive bacterium $B$. subtilis is involved in cellular elongation and sporulation through the activation of peptidoglycan hydrolases that cleave old peptidoglycan bonds in order to insert new peptidoglycan subunits (Garti-Levi et al., 2008; Domínguez-Cuevas et al., 2013; Meisner et al., 2013; Mavrici et al., 2014; Mir et al., 2015). FtsE provides energy for this process through its activity as an ATP binding protein and ATP hydrolase; FtsX is a transmembrane protein that has a cell wall hydrolaseassociated domain located on the external side of the cell membrane (Garti-Levi et al., 2008; Domínguez-Cuevas et al., 2013; Meisner et al., 2013; Sham et al., 2013; Mavrici et al., 2014; Mir et al., 2015). Together, FtsE and FtsX interact to form a dimerized FtsE/X complex that spans the bacterial cell membrane (Garti-Levi et al., 2008; Domínguez-Cuevas et al., 2013; Meisner et al., 2013). The hydrolysis of ATP by FtsE is thought to produce a conformational change in FtsX, which then activates and/or releases peptidoglycan hydrolases, which cleave the covalent bonds within the peptidoglycan structure (Domínguez-Cuevas et al., 2013; Meisner et al., 2013; Mavrici et al., 2014; Mir et al., 2015). This process is tightly controlled in order to maintain bacterial cell wall integrity, and any disruption, either through inhibition or overactivation of the hydrolases results in the inability to maintain the necessary internal pressure or withstand external environmental pressure (Bugg et al., 2011). CXCL10-mediated killing of B. anthracis via the FtsX-dependent pathway requires an active FtsE/X complex and does not simply use FtsX as a binding site for CXCL10 (Margulieux et al., 2016). FtsE/X is an intriguing antimicrobial target due to the role it has in hydrolase activation (Reith and Mayer, 2011; Vollmer, 2012; DomínguezCuevas et al., 2013; Meisner et al., 2013). Interestingly, in our previously published $B$. anthracis Sterne strain transposon mutant library screen, we identified two uncharacterized genes with putative lytic hydrolase domains, BAS0651 and lytE (Crawford et al., 2011). The requirement for an active FtsE/X for CXCL10-mediated antimicrobial activity against $B$. anthracis and the identification of two putative hydrolases from the transposon mutant library screen raises exciting possibilities that the mechanism of action of CXCL10 and its derivatives may involve dysregulation of an FtsE/X complex-associated hydrolase (Crawford et al., 2011; Domínguez-Cuevas et al., 2013; Meisner et al., 2013; Sham et al., 2013; Bartual et al., 2014; Mavrici et al., 2014). Future studies are planned to investigate the possible role of BAS0651 and LytE, or other putative

\section{REFERENCES}

Arends, S. J. R., Kustusch, R. J., and Weiss, D. S. (2009). ATP-binding site lesions in FtsE impair cell division. J. Bacteriol. 191, 3772-3784. doi: 10.1128/JB. 00179-09

Bajaj, R., Bruce, K. E., Davidson, A. L., Rued, B. E., Stauffacher, C. V., and Winkler, M. E. (2016). Biochemical characterization of essential cell division proteins FtsX and FtsE that mediate peptidoglycan hydrolysis by PcsB in Streptococcus pneumoniae. Microbiol. Open 3, 1-15. doi: 10.1002/mbo3.366
B. anthracis cell wall hydrolases, in the antimicrobial effect of CXCL10.

The findings presented in the current study suggest a novel mechanism for FtsE/X-dependent antimicrobial activity of CXCL10 by disrupting peptidoglycan remodeling. It appears that CXCL10 disrupts the regulation of peptidoglycan synthesis and turnover leading to an increase in peptidoglycan release and cell wall breakdown that results in cell death. FtsE/X functions in Gram-positive bacteria at the intersection of bacterial growth and homeostatic peptidoglycan remodeling, making it a promising target for new antimicrobial molecules. FtsE/X is thought to exist within a larger cell wall synthesis complex, the continued study of which will further clarify the mechanism by which CXCL10 kills vegetative cells of $B$. anthracis. These findings advance our understanding of the mechanism(s) by which CXCL10 exerts its antimicrobial effect and may ultimately facilitate development of novel antimicrobial strategies such as small molecule therapeutics derived from CXCL10 that target the FtsE/X complex.

\section{AUTHOR CONTRIBUTIONS}

$\mathrm{KM}, \mathrm{BL}, \mathrm{VT}$, and AS: performed the experiments presented in this work. $\mathrm{KM}$ and $\mathrm{MH}$ : wrote the manuscript. KM, BL, VT, AS, JB, $\mathrm{RN}$, and $\mathrm{MH}$ : designed the experiments, analyzed the resulting data, and reviewed and revised the manuscript.

\section{FUNDING}

This work was supported by the National Institutes of Health/National Institute of Allergy and Infectious Diseases grant R01 AI099097 (MH) and the National Institutes of Health grant T32 AI055432 (KM).

\section{ACKNOWLEDGMENTS}

We thank Barbara Mann, Girija Ramakrishnan, and members of their laboratories at the University of Virginia for helpful discussions. We also thank George Liechti (Uniformed Services University of the Health Sciences, Bethesda, MD, USA) and Stephen A. Morse (Centers for Disease Control and Prevention, Atlanta, GA, USA) for providing helpful comments on the manuscript. Confocal microscopy was performed with a Zeiss LSM 880 confocal microscope in the University of Virginia School of Medicine Advanced Microscopy Core Facility.

Bartual, S. G., Straume, D., Stamsås, G. A., Muñoz, I. G., Alfonso, C., MartínezRipoll, M., et al. (2014). Structural basis of PcsB-mediated cell separation in Streptococcus pneumoniae. Nat. Commun. 5:3842. doi: 10.1038/ncomms4842

Bernatchez, S., Francis, F. M., Salimnia, H., Beveridge, T. J., Li, H., and Dillon, J. A. (2000). Genomic, transcriptional and phenotypic analysis of $\mathrm{ftsE}$ and $\mathrm{ftsX}$ of Neisseria gonorrhoeae. DNA Res. 7, 75-81. doi: 10.1093/dnares/7.2.75

Boersma, M. J., Kuru, E., Rittichier, J. T., VanNieuwenhze, M. S., Brun, Y. V., and Winkler, M. E. (2015). Minimal peptidoglycan turnover in wild-type and PG hydrolase and cell division mutants of Streptococcus pneumoniae D39 growing 
planktonically and in host-relevant biofilms. J. Bacteriol. 197, 3472-3485. doi: 10.1128/JB.00541-15

Booth, V., Keizer, D. W., Kamphuis, M. B., Clark-Lewis, I., and Sykes, B. D. (2002). The CXCR3 binding chemokine IP-10/CXCL10: structure and receptor interactions. Biochemistry 41, 10418-10425. doi: 10.1021/bi026020q

Brogden, K. A. (2005). Antimicrobial peptides: pore formers or metabolic inhibitors in bacteria? Nat. Rev. Microbiol. 3, 238-250. doi: 10.1038/ nrmicro1098

Bugg, T. D. H., Braddick, D., Dowson, C. G., and Roper, D. I. (2011). Bacterial cell wall assembly: still an attractive antibacterial target. Trends Biotechnol. 29, 167-173. doi: 10.1016/j.tibtech.2010.12.006

Chopra, I., and Roberts, M. (2001). Tetracycline antibiotics: mode of action, applications, molecular biology, and epidemiology of bacterial resistance. Microbiol. Mol. Biol. Rev. 65, 232-260. doi: 10.1128/MMBR.65.2.232-260.2001

Cole, A. M., Ganz, T., Liese, A. M., Burdick, M. D., Liu, L., and Strieter, R. M. (2001). Cutting edge: IFN-inducible ELR- CXC chemokines display defensinlike antimicrobial activity. J. Immunol. 167, 623-627. doi: 10.4049/jimmunol. 167.2.623

Crawford, M. A., Burdick, M. D., Glomski, I. J., Boyer, A. E., Barr, J. R., Mehrad, B., et al. (2010). Interferon-inducible CXC chemokines directly contribute to host defense against inhalational anthrax in a murine model of infection. PLoS Pathog. 6:e1001199. doi: 10.1371/journal.ppat.1001199

Crawford, M. A., Lowe, D. E., Fisher, D. J., Stibitz, S., Plaut, R. D., Beaber, J. W., et al. (2011). Identification of the bacterial protein FtsX as a unique target of chemokine-mediated antimicrobial activity against Bacillus anthracis. Proc. Natl. Acad. Sci. U.S.A. 108, 17159-17164. doi: 10.1073/pnas.1108495108

Crawford, M. A., Zhu, Y., Green, C. S., Burdick, M. D., Sanz, P., Alem, F., et al. (2009). Antimicrobial effects of interferon-inducible CXC chemokines against Bacillus anthracis spores and bacilli. Infect. Immun. 77, 1664-1678. doi: 10.1128/IAI.01208-08

de Leeuw, E., Graham, B., Phillips, G. J., ten Hagen-Jongman, C. M., Oudega, B., and Luirink, J. (1999). Molecular characterization of Escherichia coli FtsE and FtsX. Mol. Microbiol. 31, 983-993. doi: 10.1046/j.1365-2958.1999.01245.x

Domínguez-Cuevas, P., Porcelli, I., Daniel, R. A., and Errington, J. (2013). Differentiated roles for MreB-actin isologues and autolytic enzymes in Bacillus subtilis morphogenesis. Mol. Microbiol. 89, 1084-1098. doi: 10.1111/mmi.12335

Durr, M., and Peschel, A. (2002). Chemokines meet defensins: the merging concepts of chemoattractants and antimicrobial peptides in host defense. Infect. Immun. 70, 6515-6517. doi: 10.1128/IAI.70.12.6515-6517.2002

Frederick, M. J., and Clayman, G. L. (2001). Chemokines in cancer. Expert Rev. Mol. Med. 3, 1-18. doi: 10.1017/S1462399401003301

Garti-Levi, S., Hazan, R., Kain, J., Fujita, M., and Ben-Yehuda, S. (2008). The FtsEX ABC transporter directs cellular differentiation in Bacillus subtilis. Mol. Microbiol. 69, 1018-1028. doi: 10.1111/j.1365-2958.2008.06340.x

Girardin, S. E., Boneca, I. G., Viala, J., Chamaillard, M., Labigne, A., Thomas, G., et al. (2003a). Nod2 is a general sensor of peptidoglycan through muramyl dipeptide (MDP) detection. J. Biol. Chem. 278, 8869-8872.

Girardin, S. E., Travassos, L. H., Hervé, M., Blanot, D., Boneca, I. G., Philpott, D. J., et al. (2003b). Peptidoglycan molecular requirements allowing detection by Nod1 and Nod2. J. Biol. Chem. 278, 41702-41708.

Holdren, G. O., Rosenthal, D. J., Yang, J., Bates, A. M., Fischer, C. L., Zhang, Y., et al. (2014). Antimicrobial activity of chemokine CXCL10 for dermal and oral microorganisms. Antibiotics 3, 527-539. doi: 10.3390/antibiotics3040527

Kohanski, M. A., Dwyer, D. J., and Collins, J. J. (2010). How antibiotics kill bacteria: from targets to networks. Nat. Rev. Microbiol. 8, 423-435. doi: 10.1038/ nrmicro2333

Kolb, H. C., Finn, M. G., and Sharpless, K. B. (2001). Click chemistry: diverse chemical function from a few good reactions. Angew. Chem. Int. Ed. 40, 2004-2021. doi: 10.1002/1521-3773(20010601)40:11<2004::AID-ANIE2004> 3.0.CO;2-5

Kuru, E., Hughes, H. V., Brown, P. J., Hall, E., Tekkam, S., Cava, F., et al. (2012). In Situ probing of newly synthesized peptidoglycan in live bacteria with fluorescent D-amino acids. Angew. Chem. Int. Ed. Engl. 51, 12519-12523. doi: 10.1002/anie.201206749

Kuru, E., Tekkam, S., Hall, E., Brun, Y. V., and Van Nieuwenhze, M. S. (2015). Synthesis of fluorescent $\mathrm{D}$-amino acids and their use for probing peptidoglycan synthesis and bacterial growth in situ. Nat. Protoc. 10, 33-52. doi: 10.1038/ nprot.2014.197
Liechti, G., Kuru, E., Packiam, M., Hsu, Y.-P., Tekkam, S., Hall, E., et al. (2016). Pathogenic Chlamydia lack a classical sacculus but synthesize a narrow, midcell peptidoglycan ring, regulated by MreB, for cell division. PLoS Pathog. 12:e1005590. doi: 10.1371/journal.ppat.1005590

Liechti, G. W., Kuru, E., Hall, E., Kalinda, A., Brun, Y. V., VanNieuwenhze, M., et al. (2014). A new metabolic cell-wall labelling method reveals peptidoglycan in Chlamydia trachomatis. Nature 506, 507-510. doi: 10.1038/nature 12892

Lovering, A. L., Safadi, S. S., and Strynadka, N. C. J. (2012). Structural perspective of peptidoglycan biosynthesis and assembly. Annu. Rev. Biochem. 81, 451-478. doi: 10.1146/annurev-biochem-061809-112742

Loving, C. L., Osorio, M., Kim, Y.-G., Nuñez, G., Hughes, M. A., and Merkel, T. J. (2009). Nod1/Nod2-mediated recognition plays a critical role in induction of adaptive immunity to anthrax after aerosol exposure. Infect. Immun. 77, 4529-4537. doi: 10.1128/IAI.00563-09

Margulieux, K. R., Fox, J. W., Nakamoto, R. K., and Hughes, M. A. (2016). CXCL10 acts as a bifunctional antimicrobial molecule against Bacillus anthracis. MBio 7:e334-16. doi: 10.1128/mBio.00334-16

Mavrici, D., Marakalala, M. J., Holton, J. M., Prigozhin, D. M., Gee, C. L., Zhang, Y. J., et al. (2014). Mycobacterium tuberculosis FtsX extracellular domain activates the peptidoglycan hydrolase, RipC. Proc. Natl. Acad. Sci. U.S.A. 111, 8037-8042. doi: 10.1073/pnas.1321812111

Meisner, J., Montero Llopis, P., Sham, L.-T., Garner, E., Bernhardt, T. G., and Rudner, D. Z. (2013). FtsEX is required for CwlO peptidoglycan hydrolase activity during cell wall elongation in Bacillus subtilis. Mol. Microbiol. 89, 1069-1083. doi: $10.1111 / \mathrm{mmi} .12330$

Mir, M. A., Arumugam, M., Mondal, S., Rajeswari, H. S., Ramakumar, S., and Ajitkumar, P. (2015). Mycobacterium tuberculosis cell division protein, FtsE, is an ATPase in dimeric form. Protein J. 34, 35-47. doi: 10.1007/s10930-0149593-7

Mir, M. A., Rajeswari, H. S., Veeraraghavan, U., and Ajitkumar, P. (2006). Molecular characterisation of $\mathrm{ABC}$ transporter type FtsE and FtsX proteins of Mycobacterium tuberculosis. Arch. Microbiol. 185, 147-158. doi: 10.1007/ s00203-005-0079-z

Mock, M., and Fouet, A. (2001). Anthrax. Annu. Rev. Microbiol. 55, 647-671. doi: 10.1146/annurev.micro.55.1.647

Nguyen, L. T., and Vogel, H. J. (2012). Structural perspectives on antimicrobial chemokines. Front. Immunol. 3:384. doi: 10.3389/fimmu.2012.00384

Novak, R., Charpentier, E., Braun, J. S., and Tuomanen, E. (2000). Signal transduction by a death signal peptide: uncovering the mechanism of bacterial killing by penicillin. Mol. Cell 5, 49-57. doi: 10.1016/S1097-2765(00)80402-5

Packiam, M., Weinrick, B., Jacobs, W. R., and Maurelli, A. T. (2015). Structural characterization of muropeptides from Chlamydia trachomatis peptidoglycan by mass spectrometry resolves "chlamydial anomaly". Proc. Natl. Acad. Sci. U.S.A. 112, 11660-11665. doi: 10.1073/pnas. 1514026112

Philpott, D. J., Sorbara, M. T., Robertson, S. J., Croitoru, K., and Girardin, S. E. (2014). NOD proteins: regulators of inflammation in health and disease. Nat. Rev. Immunol. 14, 9-23. doi: 10.1038/nri3565

Popham, D. L. (2013). Visualizing the production and arrangement of peptidoglycan in Gram-positive cells. Mol. Microbiol. 88, 645-649. doi: 10.1111/ mmi. 12212

Reddy, M. (2007). Role of FtsEX in cell division of Escherichia coli: viability of ftsEX mutants is dependent on functional Sufl or high osmotic strength. J. Bacteriol. 189, 98-108. doi: 10.1128/JB.01347-06

Reith, J., and Mayer, C. (2011). Peptidoglycan turnover and recycling in Grampositive bacteria. Appl. Microbiol. Biotechnol. 92, 1-11. doi: 10.1007/s00253011-3486-x

Rossi, D., and Zlotnik, A. (2000). The biology of chemokines and their receptors. Annu. Rev. Immunol. 18, 217-242. doi: 10.1146/annurev.immunol.18.1.217

Schmidt, K. L., Peterson, N. D., Kustusch, R. J., Wissel, M. C., Graham, B., Phillips, G. J., et al. (2004). A predicted ABC transporter, FtsEX, is needed for cell division in Escherichia coli. J. Bacteriol. 186, 785-793. doi: 10.1128/JB.186.3. 785-793.2004

Schneider, C. A., Rasband, W. S., and Eliceiri, K. W. (2012). NIH Image to ImageJ: 25 years of image analysis. Nat. Methods 9, 671-675. doi: 10.1038/nmeth. 2089

Schutte, K. M., Fisher, D. J., Burdick, M. D., Mehrad, B., Mathers, A. J., Mann, B. J., et al. (2016). Escherichia coli pyruvate dehydrogenase complex is an important 
component of CXCL10-mediated antimicrobial activity. Infect. Immun. 84, 320-328. doi: 10.1128/IAI.00552-15

Sham, L., Jensen, K. R., Bruce, K. E., and Winkler, M. E. (2013). Involvement of FtsE ATPase and FtsX extracellular loops 1 and 2 in FtsEX-PcsB complex function in cell division of Streptococcus pneumoniae D39. MBio 4:e431-13. doi: 10.1128/mBio.00431-13

Sobhanifar, S., King, D. T., and Strynadka, N. C. (2013). Fortifying the wall: synthesis, regulation and degradation of bacterial peptidoglycan. Curr. Opin. Struct. Biol. 23, 695-703. doi: 10.1016/j.sbi.2013.07.008

Swaminathan, G. J., Holloway, D. E., Colvin, R. A., Campanella, G. K., Papageorgiou, A. C., Luster, A. D., et al. (2003). Crystal structures of oligomeric forms of the IP-10/CXCL10 chemokine. Structure 11, 521-532. doi: 10.1016/ S0969-2126(03)00070-4

Tipper, D. J., and Strominger, J. L. (1965). Mechanism of action of penicillins: a proposal based on their structural similarity to acyl-D-alanyl-D-alanine. Proc. Natl. Acad. Sci. U.S.A. 54, 1133-1141. doi: 10.1073/pnas.54.4.1133

Turner, R. D., Vollmer, W., and Foster, S. J. (2014). Different walls for rods and balls: the diversity of peptidoglycan. Mol. Microbiol. 91, 862-874. doi: 10.1111/ mmi. 12513

Typas, A., Banzhaf, M., Gross, C. A., and Vollmer, W. (2011). From the regulation of peptidoglycan synthesis to bacterial growth and morphology. Nat. Rev. Microbiol. 10, 123-136. doi: 10.1038/nrmicro2677

Vollmer, W. (2012). Bacterial growth does require peptidoglycan hydrolases. Mol. Microbiol. 86, 1031-1035. doi: 10.1111/mmi.12059

Vollmer, W., and Seligman, S. J. (2010). Architecture of peptidoglycan: more data and more models. Trends Microbiol. 18, 59-66. doi: 10.1016/j.tim.2009. 12.004
Wise, E. M., and Park, J. T. (1965). Penicillin: its basic site of action as an inhibitor of a peptide cross-linking reaction in cell wall mucopeptide synthesis. Proc. Natl. Acad. Sci. U.S.A. 54, 75-81. doi: 10.1073/pnas.54.1.75

Yang, D., Chen, Q., Hoover, D. M., Staley, P., Tucker, K. D., Lubkowski, J., et al. (2003). Many chemokines including CCL20/MIP-3alpha display antimicrobial activity. J. Leukoc. Biol. 74, 448-455. doi: 10.1189/jlb.0103024

Yeaman, M. R., and Yount, N. Y. (2007). Unifying themes in host defence effector polypeptides. Nat. Rev. Microbiol. 5, 727-740. doi: 10.1038/nrmicro1744

Yung, S. C., and Murphy, P. M. (2012). Antimicrobial chemokines. Front. Immunol. 3:276. doi: 10.3389/fimmu.2012.00276

Zlotnik, A., and Yoshie, O. (2000). Chemokines: a new classification system and their role in immunity. Immunity 12, 121-127. doi: 10.1016/S1074-7613(00) 80165-X

Zlotnik, A., and Yoshie, O. (2012). The chemokine superfamily revisited. Immunity 36, 705-716. doi: 10.1016/j.immuni.2012.05.008

Conflict of Interest Statement: The authors declare that the research was conducted in the absence of any commercial or financial relationships that could be construed as a potential conflict of interest.

Copyright (C) 2017 Margulieux, Liebov, Tirumala, Singh, Bushweller, Nakamoto and Hughes. This is an open-access article distributed under the terms of the Creative Commons Attribution License (CC BY). The use, distribution or reproduction in other forums is permitted, provided the original author(s) or licensor are credited and that the original publication in this journal is cited, in accordance with accepted academic practice. No use, distribution or reproduction is permitted which does not comply with these terms. 